\title{
Principal accomplishments in the scientific theory of gearing
}

\author{
Stephen Radzevich* \\ EATON Corp., Detroit, USA
}

\begin{abstract}
An in-depth analysis of the accomplishments in the theory of gearing has been undertaken by the author. The main results of the performed analysis are outlined in the paper in a chronological order. Two periods of time are proposed to be considered: pre-Eulerian and post-Eulerian time of the evolution of the gear art. No principal accomplishments in the theory of gearing were attained in the pre-Eulerian period of evolution of gearing. It is stated that scientific theory of gearing is originated from the publication by Leonhard Euler of two of his famous papers (1760). The main theorem of parallel-axes gearing, or, in other words, the "conjugate action law", is loosely attributed to R. Willis (1841), which is not correct. Ch. Camus was the first (1733), who has carried out a research on this subject, however he failed to formulate this law of gearing correctly. In the final form the theorem was known to L. Euler and to F. Savary. Therefore, it is proposed to refer to the main theorem of parallel-axes gearing as to the "Camus-Euler-Savary theorem of gearing" (or just as to the "CES-theorem of gearing", for simplicity). A huge mistake in the theory of gearing was committed by T. Olivier (1842). The effect of this mistake onto the evolution of the theory of gearing is discussed. Contributions by G. Grant (1887), and by V. Shishkov (1948), that is, his well-known equation of contact, $\mathbf{n} \cdot \mathbf{V}_{\Sigma}=0$, are outlined. Introduced in around 2008, concept of the operating base pitch in a gear pair considered in detail. Latest accomplishments in the theory of gearing are summarized and briefly discussed in the paper. These accomplishments form the foundation of the self-consistent scientific theory of gearing (Radzevich, S.P., 2012, 2018). The scientific theory of gearing is not threatened with destruction, but only superstructure and development are extected (every scientific theory features this property).
\end{abstract}

\section{Introduction}

The art and science of gearing have their roots before the Common Era. Yet many engineers and researchers continue to delve into the areas where improvements are necessary, seeking to quantify, establish, and codify methods to make gears meet the ever-widening needs of advancing technology. It should be stressed here that the scientific theory of gearing is a foundation to design, production, and application of perfect gears and geared mechanisms.

Besides gears and gear transmissions are investigated for a long while, the nowadays knowledge of the gear theory is poor and is completely insufficient. Not much is contributed to the theory of gearing since the time of Leonhard Euler (the middle of the XVIII century). Moreover, the author is doubtful that nowadays all the principal accomplishments in the theory of gearing are known to all the gear researchers, those who are actively involved in the research in the field.

It makes sense to make a brief overview on the evolution of the scientific theory of gearing ${ }^{\mathrm{a}}$. This will

\footnotetext{
${ }^{a}$ It should be stressed here that in the paper the principal accomplishments only in the theory of gearing, and not in the gear art in a whole are discussed. Therefore, novel designs of gearing (e.g.,
}

help us to identify what is already done in the field to this end, where we are now, and what to do in the future. Such an analysis needs to be carried out to credit right gear researchers with their accomplishments. Unfortunately, in the meantime, numerous of the achievements in the field of gearing cannot be attributed to a right gear researcher, as the corresponding name is not known. For example, it is not known who should be credited with the (a) condition of contact of gear teeth, (b) requirement to keep the base pitches of a gear and a mating pinion equal to each other, and so forth. These accomplishments are of prime importance to the scientific theory of gearing.

Motivation: The necessity of "cleaning" of the gear science from incorrect, wrong, and loosely statements, as well as from other inconsistencies is the main reason to write this paper.

The bottom-line is as follows: All the principal accomplishments in the theory of gearing have to be identified, and each gear researcher who has contributed significantly to the theory of gearing, deserves to be credited with the corresponding scientific result.

Novikov gearing, as well, as others) got no consideration here, as in a whole they are covered by the scientific theory of gearing. 


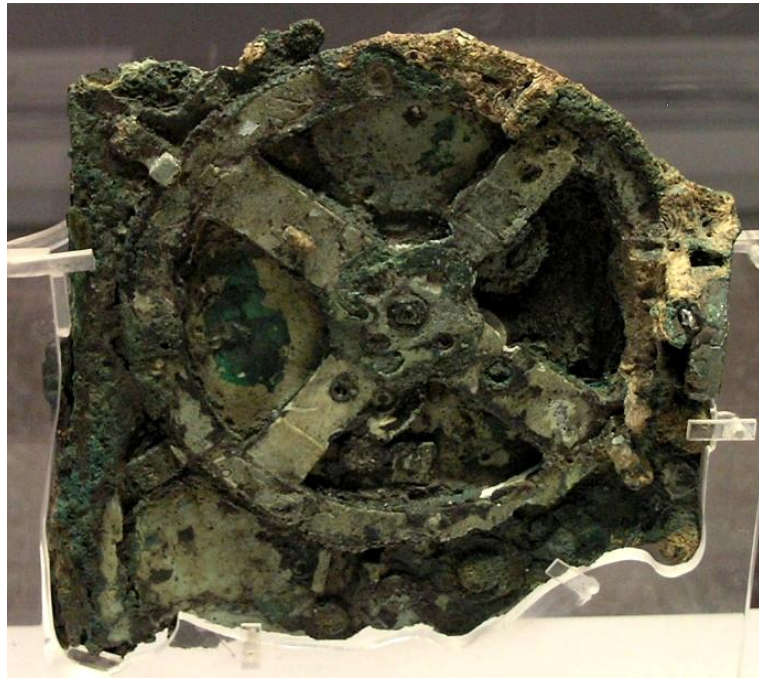

(a)

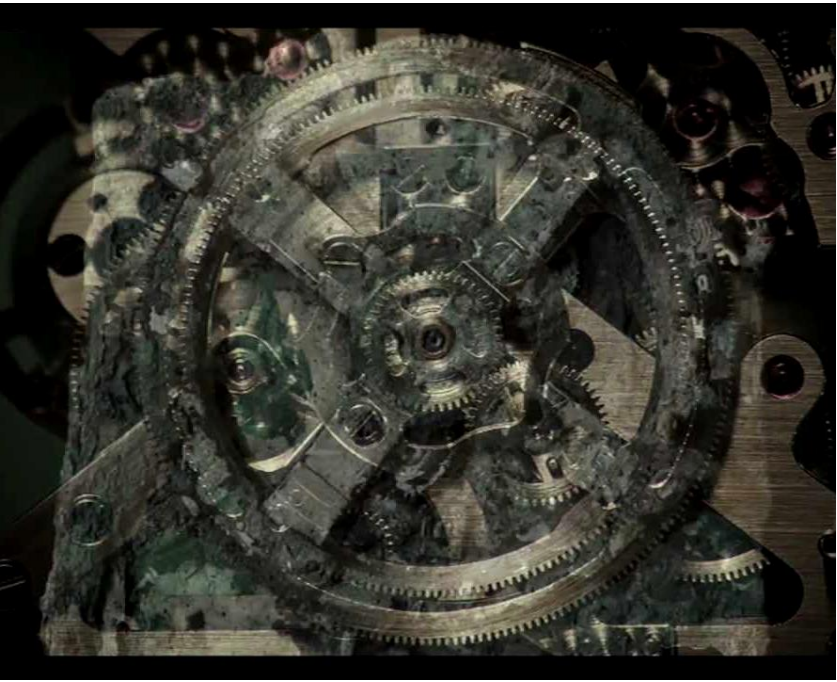

(b)

Fig. 1. The Antikythera mechanism, (100 BC to $205 \mathrm{BC}$ ): (a) an image of the original mechanism, and (b) the mechanism, overlapped with the image of the corresponding replica.

Those, who don't know their own history have no chance for success in the future.

\section{Preliminary remarks}

Gears are used to transmit and transform a rotation from an input shaft to an output shaft. Depending on a particular application, gearings have to meet certain additional requirements, that is, high accuracy of the transmission of rotation, high power density (or powerto-weight ratio), and so forth.

The development and investigation of gearings with a constant angular velocity ratio (that is, gearings for which the equality $\omega_{p} / \omega_{g}=$ const is valid) is one of the main goals of the scientific theory of gearing. Gearings with a constant angular velocity ratio [or, more generally (for non-circular gearings), with a prespecified function of the angular velocity ratio] are commonly called "perfect gearings". They are also covered by the scientific theory of gearing.

\section{Main periods in the evolution of the theory of gearing}

As it was earlier (circa 2012) proposed by the author [1], [2], the evolution of the theory of gearing falls into two periods, namely: (a) pre-Eulerian period of the gear art, and (b) post-Eulerian period of the theory of gearing, which are separated from one another by the time of (c) fundamental contribution by L. Euler. The principal accomplishments in the scientific theory of gearing are considered below in a chronological order in alignment with the just mentioned two periods of evolution. It is believed that all (or, at least, almost all) principal accomplishments are covered in the paper.

\subsection{Pre-Eulerian period of the gear art}

Shown in Fig. 1, is the Antikythera mechanism (100 to $205 \mathrm{BC}$ ). The Antikythera mechanism is the oldest known so far artefact that consists gears.

The art of gearing was carried through the European Dark Ages, appearing in Islamic instruments such as the geared astrolabes that were used to calculate the positions of the celestial bodies. Perhaps the art was relearned by the clock- and instrument-making artisans of XIV century Europe, or perhaps some crystallizing ideas and mechanisms were imported from the East after the crusades of the XI through the XIII centuries.

The history of evolution of the gear art can be traced back to the time of Aristotle (384-322 BC), or even to

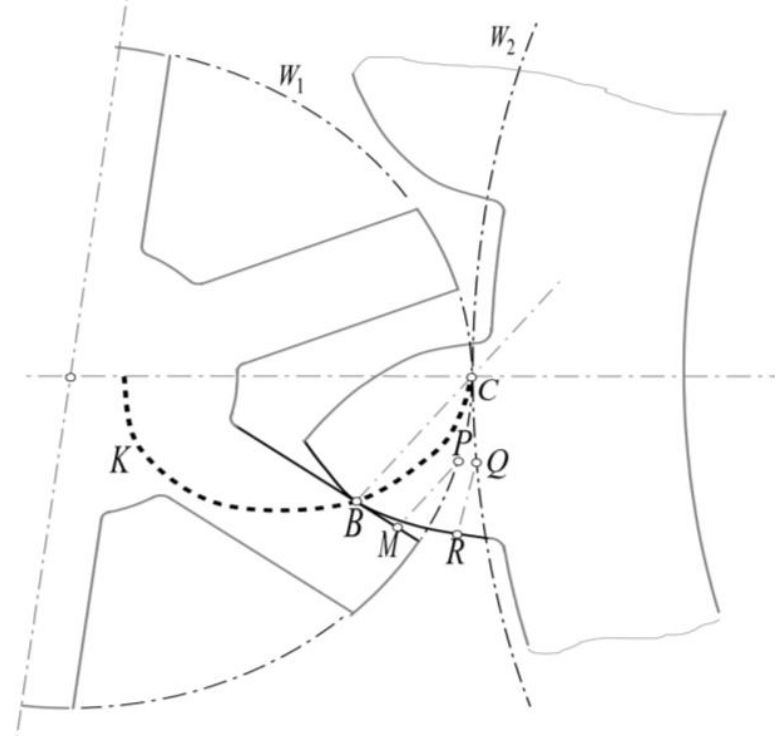

Fig. 2. Illustration of Camus' gearing principle (1733). (Adapted from [1]). 


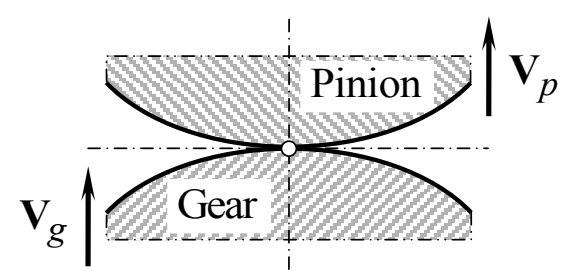

(a)

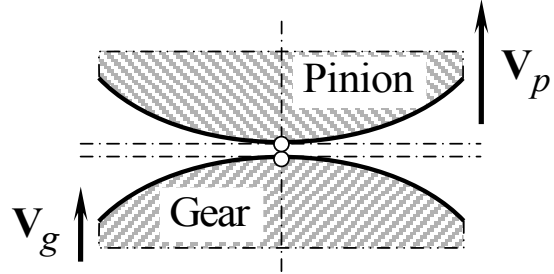

(b)

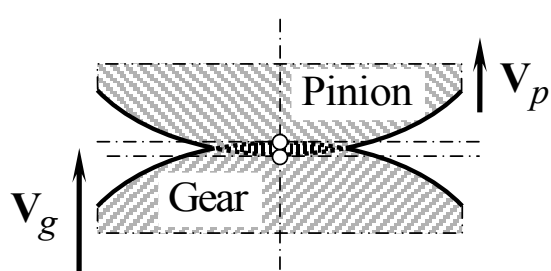

(c)

Fig. 3. Condition of contact of a gear and a mating pinion tooth flanks: (a) perfect contact, $\mathbf{V}_{g}=\mathbf{V}_{p}$, (b) separation, $\mathbf{V}_{g}<\mathbf{V}_{p}$, and (c) interference of the tooth flanks, $\mathbf{V}_{g}>\mathbf{V}_{p}$.

the earlier times. Numerous famous names have indicated more or less interest to gears and gear drives. Leonardo da Vinci (1452 - 1519), Albrecht Dürer (1471 -1528), Robert Hooke (1635-1703), and numerous others can be mentioned in this regard. Three famous names have to be mentioned here. They are: Gerard Desargues (1591-1661), Philippe de la Hire (16401718), Charles Etienne Louis Camus (1699-1768). The results of the research obtained by these scientists are very close to the origin of the scientific theory of gearing. In particular, Camus was close to discover the "conjugate action law" for the case of parallel-axes gearing [3], (further, " $P_{a}$-gearing", for simplicity). Unfortunately, Camus loosely assumed that the line of action, $L A$, in perfect gearing can be shaped in a form of a planar curve, as illustrated in Fig. 2. The line of action, $C B K$, cannot be a curve, as a force acts only along a straight line, that is, along a straight line of action, and not along a curve. Therefore, it is incorrect to grant Camus with the discovery of the "conjugate action law".

The condition of contact of the interacting tooth flanks is the only contribution to the scientific theory of gearing attained in the pre-Eulerian period of the gear art. The initially proposed for a more general case condition of contact of two machine elements can also be implemented with respect to gears. This condition is schematically illustrated in Fig. 3.

The condition of contact requires that at contact point both a gear and a mating pinion tooth flanks that interact with one another, have to travel with an equal velocities along the common perpendicular, that is, the equality $\mathbf{V}_{g} \equiv \mathbf{V}_{p}$ has to be valid (see Fig. 3,a). The relative velocity is zero in this case $\left(\mathbf{V}_{\text {rel }}=0\right)$. In a case

${ }^{\mathrm{b}}$ In 1666, R. Hooke demonstrated for The Royal Society a model of gearing that he has invented earlier. Later on the gearing of this kind Hooke described in his 1674 book "Lectiones Cutlerianae". The gearing of this particular kind is nowadays known as White's gearing. May be this is somehow associated with Mr. Christipher White of London who manufactured a microscope for R. Hooke.
$\mathbf{V}_{g}<\mathbf{V}_{p}$, the components 1 and 2 separate from one another (Fig. 3,b), and the relative velocity is of a positive value in this case $\left(\mathbf{V}_{\text {rel }}>0\right)$. Inversely, in a case $\mathbf{V}_{g}>\mathbf{V}_{p}$, the components 1 and 2 interfere into one another (Fig. 3,c). The relative velocity is of a negative value in this case $\left(\mathbf{V}_{\text {rel }}<0\right)$. None of these two cases is permissible in perfect gearing.

The condition of contact $(\# 0)^{c}$ is important to the theory of gearing. Unfortunately, it is not known who should be credited with this important accomplishment (may be this is because the condition of contact has been discovered for a more general case, and not for the purposes of gears).

\subsection{Fundamental contribution by $L$. Euler}

This was Leonhard Euler (1707 - 1783) who proved (in the first half of 1750s) that involute of a circle is the best planar curve that fits to shape a gear tooth profile in perfect $P_{a}$-gearing [4], [5] (\#1).

In the Euler's first paper on gears [4] (written in the first half of the 1750s) he proved that the tooth profile sliding is inevitable. As for the shape of the teeth, Euler in this paper did not succeed in going beyond what Camus had already done. However, Euler's paper [5] (written presumably ten years later) is very original. In this paper Euler gave a formula that is equivalent to the Euler-Savary formula ${ }^{\mathrm{d}}$ in the nowadays interpretation.

Euler did not investigate general planar motion at a particular instant of time. Instead, he studied the form of the teeth of gear wheels. The general validity of the

" The item " $\# 0$ " corresponds to the item, labeled " 0 ", in Fig. 11. Fig. 11 is introduced below, at the end of the paper. The similar is applicable to the rest items below.

d The consequences from the Euler-Savary formula (the involute tooth profile, and the conjugate action law) are important to the theory of gearing, while the formula itself is less important. This is the only reason for the Euler-Savary formula is not indicated in Fig. 11. 


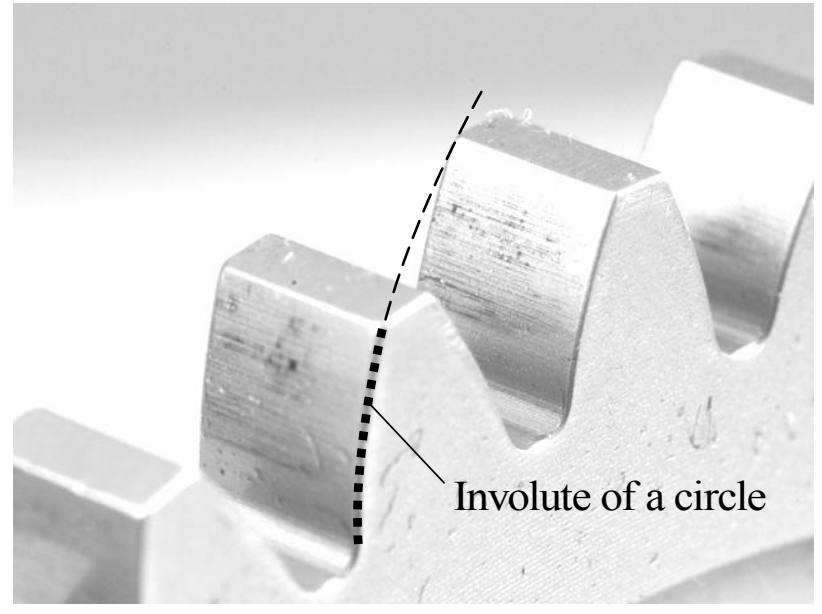

Fig. 4. Involute gear teeth.

formula that he discovered is an accidental spin-off of his research.

The formula has an amazing interpretation. Euler considered a reduced case of his formula that is valid for a continuous rotation of the gears. The tooth profiles then are involutes of the circles. At this moment Euler discovered involute gearing.

Involute tooth profile is the only kind of the tooth profile that can be used to design conjugate gear pairs (Fig. 4). The kinematics and geometry of involute gearing is investigated so extensively that there is no need to discuss this gearing here more in detail, as it is trivial, and is outlined in textbooks on machine and mechanisms theory.

The scientific theory of gearing is originated from application of an involute of a circle to shape gear teeth in $P_{a}$-gearing. Involute of a circle was known to mathematicians long before the time, when L. Euler proposed to use this planar curve to shape gear teeth in perfect $P_{a}$-gearing.

The proposed $(\sim 1760)$ by L. Euler perfect parallelaxes involute gearing is considered as the origin of the scientific theory of gearing.

\subsection{Post-Eulerian period of evolution of the theory of gearing}

Since the time of the fundamental contribution by $L$. Euler the research in the field of gearing got a significant impulse.

\subsubsection{Fundamental theorem of gearing (for the case of parallel-axes gearing)}

It is likely the fundamental theorem of $P_{a}$-gearing (also known as the conjugate action law) is the first principal accomplishment contributed by L. Euler and Felix Savary $(1797-1841)$ to the scientific theory of gearing in the post-Eulerian period (\#2). Regardless of the theorem was known to Euler, and to Savary, it got an extensive recognition in Europe due to publication of the famous book by Robert Willis [6]. Because of this the fundamental theorem of $P_{a}$-gearing (Fig. 5) is often referred to as the Willis' theorem.

Fundamental theorem of gearing (according to R. Willis): The angular velocities of the two pieces are to each other inversely as the segments into which the "line of action" divides the line of centers, or inversely as the perpendiculars from centers of motion upon the line of action.

Nowadays, this theorem is commonly referred to as the "Camus-Euler-Savary fundamental theorem of gearing" (or just "CES-fundamental theorem of gearing”, for simplicity).

In $P_{a}$-gearing, the line of action, $L A$, and the path

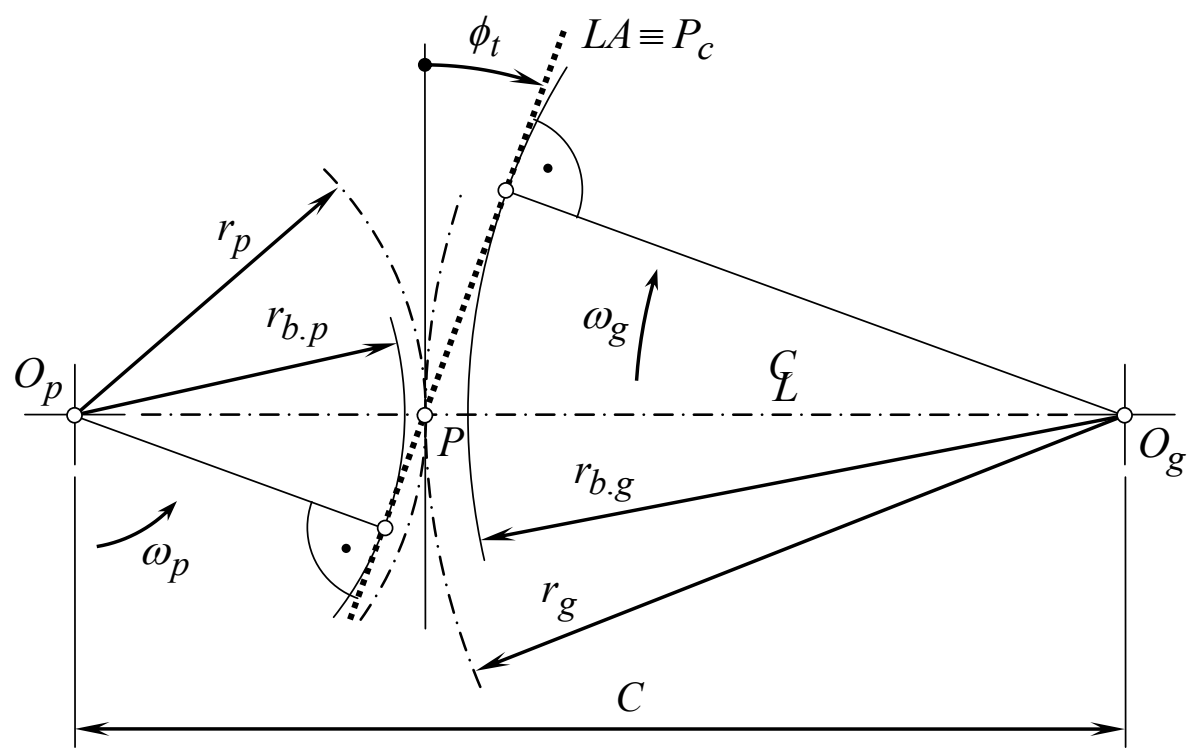

Fig. 5. An illustration of the fundamental theorem of gearing (in a case of parallel-axes gearing). 
of contact, $P_{a}$, are two straight lines that align with one another. The fundamental theorem of gearing gives an insight to make difference between these two lines, $L A$ and $P_{a}$. Unfortunately, in the meantime, this difference is not recognized by most of the gear researchers.

\subsubsection{A mistake committed by Theodore Olivier}

The research in the field of theory of gearing has been significantly affected by Theodore Olivier (1793 1853), who in 1842 has published his famous book on theory of gearing [7]. By the way, the book by Olivier [7] is the first book ever titled as "Theory of gearing".

In his book [7], T. Olivier proposed two methods for generating tooth flanks of gears (\#3). These methods are commonly referred to as the first and the second Olivier's methods of generating enveloping surfaces. Both the Olivier's methods are incorrect as in his research $T$. Olivier loosely ignored the condition of conjugacy of the interacting tooth flanks of a gear, and a mating pinion, $\mathscr{P}$. Instead, he considered the tooth flanks and $\mathscr{O}$ just as the enveloping surfaces, which is incorrect. The condition of conjugacy of the interacting tooth flanks in the book by T. Olivier [7] is violated. The violation of the condition of conjugacy of the tooth flanks is a huge mistake in the theory of gearing.

Later on, that same mistake was committed again (1886) by Ch. Gochman [8] (\#4); it is also observed in all books by F. Litvin (1914-2017) (\#8), as well as in plenty of publications by other gear researchers.

Due to the mistake committed by T. Olivier, no perfect gears can be designed, and only approximate gears can be designed instead. There is no chance to anticipate any significant achievements designing gears in alignments with this approach.

\subsubsection{Equality of base pitches (for the case of perfect parallel-axes gearing)}

The interaction of the tooth flanks $\mathscr{P}$ and a gear and a mating pinion to a certain extent can be construed as that in a cam mechanism, especially in cases when just one pair of teeth is engaged in mesh. It is common in gearing that two or even more pairs of teeth are engaged in mesh at that same time. In order to make multiple engagements possible, base pitch in interacting tooth flanks, $\mathscr{O}$ and $\mathscr{P}$, have to be equal to one another, that is, an equality $p_{b . g}=p_{b . p}$ is a must in perfect $P_{a}$-gearing (\#5). Here, $p_{b . g}$ and $p_{b . p}$ are base pitches (Fig. 6) of a gear and a mating pinion, correspondingly. Only involute gears feature base pitch, and only involute gear pairs are capable of transmitting a uniform rotation smoothly from a driving shaft to a driven shaft. No other gear tooth profiles are capable of to ensure that. Gears with non-involute tooth profile feature no base pitches. Therefore, as in non-involute gear pairs base pitches do not exist, of course, they can

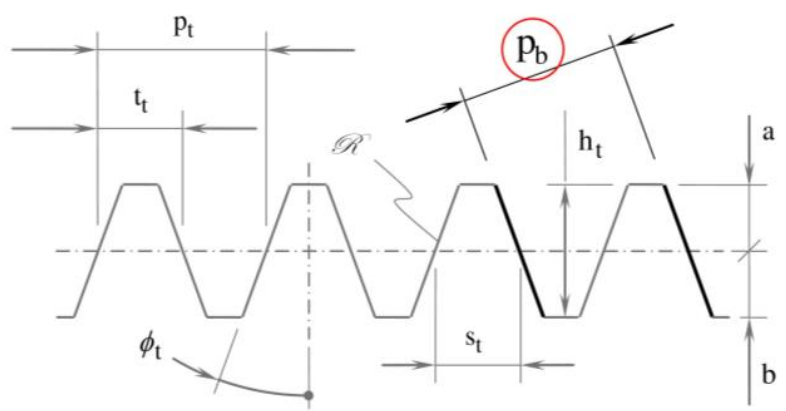

Fig. 6. Base pitch, $p_{b}$, in a basic rack, $\mathscr{R}$.

not be equal, and, ultimately, the gear pair is not capable of transmitting a uniform rotation smoothly.

The condition according to which base pitches of a gear and a mating pinion in a perfect gear pair have to be equal to one another is an important contribution to the scientific theory of gearing. Unfortunately, this significant accomplishment can not be attributed with a name of a gear researcher who was the first to derive it. Moreover, even the exact date when this accomplishment was attained also is not known. Hopefully, in the future, both, the name and the date will be identified.

\subsubsection{Gear tooth flank geometry (for the case of perfect intersected-axes gearing)}

For over a century involute $P_{a}$-gearing was the only kind of gearing for which perfect geometry of the tooth flanks (that is, the involute tooth profile) was known. The desired geometry of the tooth flanks neither in $I_{a}$ - gearing, nor in $C_{a}$ - gearing was not known for over a century.

This was George Barnard Grant (1849 - 1917) who proposed (January 14, 1887) a correct method of generation of the geometry of tooth flanks in perfect $I_{a}$ - gearing [9] (\#6).

The Grant's achievement got no extensive application in the industry, as for a long while (and even nowadays) the industry was satisfied with approximate gears that are easier in production.

On the author's opinion, G. Grant underestimated his contribution to the scientific theory of gearing. There is no evidence that nowadays researchers value the Grant's achievement properly.

\subsubsection{Shishkov equation of contact, $\mathbf{n} \cdot \mathbf{V}_{\Sigma}=0$}

As the theory of gearing evolves, new requirements to the theory arose. In particular, the considered in section 3.1 condition of contact (see Fig. 3) required an analytical representation. Numerous attempts were undertaken to derive an appropriate equation that reflects proper condition of contact of a gear, $\&$, and a mating pinion, $\mathscr{P}$, tooth flanks. 
In 1940s - early 1950s, Prof. V.A. Shiskov proposed an equation to describe the condition of contact of the tooth flanks, $\mathscr{O}$ and $[10],[11](\# 7)$ :

$$
\mathbf{n} \cdot \mathbf{V}_{\Sigma}=0
$$

Here, $\mathbf{n}$ is the unit vector of the common perpendicular, and $\mathbf{V}_{\Sigma}$ is linear velocity vector of the instantaneous resultant motion of the gear and the mating pinion.

Equation (1) is based on that a common point(s) of contact, the linear velocity vector of the instantaneous resultant motion of the gear and the mating pinion, $\mathbf{V}_{\Sigma}$, and the unit vector of the common perpendicular, $\mathbf{n}$, have to be perpendicular to one another.

Shishkov equation of contact [see Eq. (1)] is extensively used nowadays by many of gear researchers. Unfortunately, this equation is often loosely supposed to be an equation of conjugacy, which is not correct.

The interested reader may wish to go to [12] for more details on Shishkov equation of contact. tooth flanks, and $\mathscr{P}$, at a point of their contact (\#9).

The equation of the "indicatrix of conformity, $C n f_{R}(\mathscr{O})$ " at a point of contact of a gear tooth flank, and the a mating pinion tooth flank, $\mathscr{O}$, is defined of the following structure (Fig. 7):

$$
\begin{aligned}
C n f_{R}(\mathscr{O P}) & \Rightarrow r_{c n f}(\varphi, \mu)= \\
= & r_{g}(\varphi) \operatorname{sgn} R_{g}(\varphi)+r_{p}(\varphi, \mu) \operatorname{sgn} R_{p}(\varphi, \mu)
\end{aligned}
$$

Here, $R_{g}$ and $R_{p}$ are the radii of normal curvature of a gear and a mating pinion tooth flanks; $r_{g}=\sqrt{R_{g}}$, and $r_{p}=\sqrt{R_{p}} ; \mu$ is the angle of local relative orientation of the tooth flanks, $\mathscr{G}$ and $\mathscr{P}$, at a point $K$ of their contact; and $\varphi$ is the angular parameter of the indicatrix of conformity, $\operatorname{Cnf}_{R}(\mathscr{O} / \mathscr{O})$.

Indicatrix of conformity, $\operatorname{Cnf}_{R}(\mathscr{O} / \mathscr{P})$, at a point

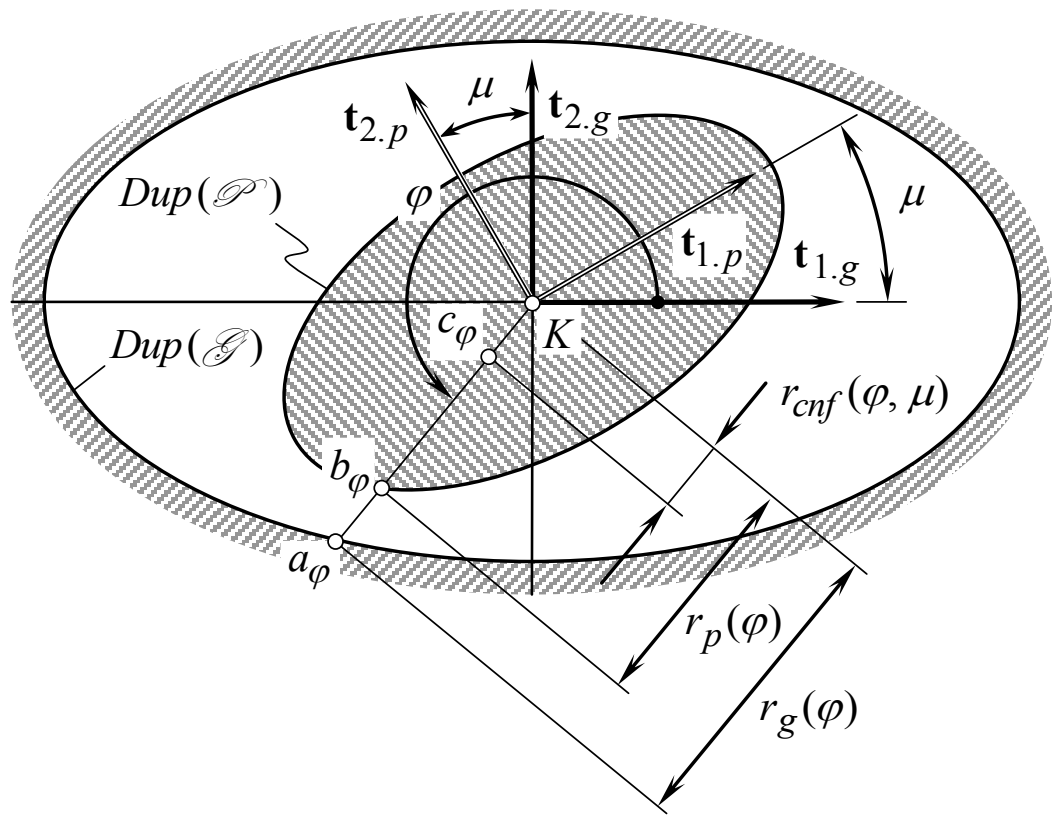

Fig. 7. On the definition of the indicatrix of conformity, $\operatorname{Cnf}_{R}(\mathscr{O} \mapsto)$, at point of contact of the tooth flanks, $\mathscr{O}$ and $\mathscr{P}$. (After Prof. S.P. Radzevich, [1]).

\subsubsection{Condition of contact: Indicatrix of conformity}

The contact geometry is specified by the discussed Shishkov equation of contact (see section 3.3.5) regardless of the actual degree of conformity of the interacting tooth flanks of a gear, $\mathscr{O}$, and a mating pinion, $\mathscr{P}$. To accommodate for the degree of conformity at a point(s) of contact of the tooth flanks, $\mathscr{O}$ and $\mathscr{O}$, a planar characteristic curve was proposed by $S$. Radzevich [1] late 1970s - at the beginning of 1980's. This characteristic curve is commonly referred to as the indicatrix of conformity, $\operatorname{Cnf} f_{R}(\mathscr{P} \mapsto)$. The indicatrix of conformity is derived on the premise of Dupin indicatrices, $\operatorname{Dup}(\mathscr{C})$ and $\operatorname{Dup}(\mathscr{O})$, of the of contact of two interacting tooth flanks, and $\mathscr{P}$, is vital for designing perfect gear pairs, and, especially, for solving a problem of synthesizing a most favorable gear pair for a particular application.

\subsubsection{Condition of conjugacy: for gearings of all kinds}

In the recent decade an extensive research on the kinematics and geometry of gearings, especially on intersected-axes gearing, and crossed-axes gearing, has been undertaken [1].

At around 2008, a condition of conjugacy of the tooth flanks, $\mathscr{O}$ and $\mathscr{P}$, in $I_{a}-$, and in $C_{a}$ - gearing was formulated by Prof. S. Radzevich (\#10). To be 


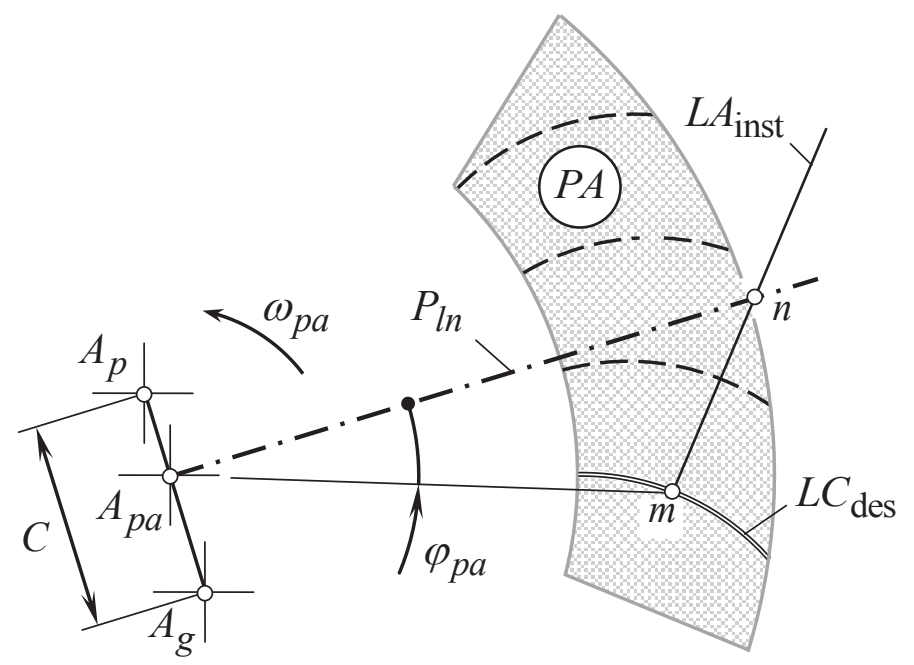

Fig. 8. Condition of conjugacy of a gear and a mating pinion tooth flanks, $\mathscr{C}$. (After Prof. S.P. Radzevich, [1])

conjugate (Fig. 8), the tooth flanks, $\mathscr{O}$ and $\mathscr{P}$, have to be designed so as to (a) retain the instant line of action, $L A_{\text {inst }}$, within the plane of action, and (b) ensure that the straight $L A_{\text {inst }}$ line intersects the axis of instant rotation, $P_{l n}$, at every angular configuration of the gears when they rotate.

The condition of conjugacy of the tooth flanks, and $\mathscr{P}$, of a gear and a mating pinion is of critical importance when designing gears for high-power-density gear pairs, as well as of gear pairs for lownoise/noiseless transmissions.

\subsubsection{Angular base pitches: Operating angular base pitch in a gear pair}

The earlier discussed in section 3.3.3 concept on equal linear base pitches of a gear and a mating pinion for the case of perfect parallel-axes gearing is evolved (Prof. S. Radzevich, circa 2008 [1]) to the most general case, that is, to the case of $C_{a}$-gearing ( $I_{a}$ - gearing is viewed here as a reduced case of $C_{a}$-gearing). For this purpose, a concept of angular operating base pitch of a gear pair, $\varphi_{b . o p}$, is introduced (\#11). A gear angular base pitch, $\varphi_{b . g}$, has to be equal to $\varphi_{b . o p}$, and the pinion angular base pitch, $\varphi_{b . p}$, also has to be equal to $\varphi_{b . o p}$ (\#12):

$$
\left\{\begin{array}{l}
\varphi_{b . g} \equiv \varphi_{b . o p} \\
\varphi_{b . p} \equiv \varphi_{b . o p}
\end{array}\right.
$$

The concept of equal angular base pitches of a gear and a mating pinion to an operating angular base pitch in the gear pair is illustrated in Fig. 9.

A set of equations [see Eq. (3)] is vital when designing perfect gearings of all kinds, that is, $P_{a}-$, $I_{a}-$, and $C_{a}$-gearings (perfect $C_{a}$-gearing is referred to as " $R$-gearing"), as well as $S_{a}$-gearing that is insensitive to the axes misalignment [1].

\subsubsection{Crossed-axes gearings with the line contact between the tooth flanks (R-gearing)}

A problem of perfect parallel-axes gearing with line contact between the tooth flanks has been sovled by Euler, who proposed (circa 1760) an involute gear tooth profile. A problem of perfect intersected-axis gearing with line contact between the tooth flanks has been sovled by Grant, who proposed (1887) a method of generation of perfect bevel gear tooth flank (again, it is likely G. Grant underestimated his contribution to the scientific theory of gearing). For the first time ever, the problem of perfect crossed-axes gearing with line contact between the tooth flanks (the so-called, $R$ - gearing) has been sovled ( 2008) by Radzevich [1] (\#13). Tooth flank $\&$ of a gear (and of a mating pinion $\mathscr{P}$ ) in $C_{a}$ - gearing is generated by a desirable line of contact, $L C_{\mathrm{des}}$, that travels together with the plane of action, $P A$, in a gear pair. The tooth flanks, $\&$ and $\mathscr{P}$, are viewed as a locus of the desirable line of contact, $L C_{\mathrm{des}}$, considered in a corresponding reference system.

\subsubsection{A scientific classification of gearings}

An extensive use of vector representation of gear pairs made possible the development of a scientific classification of vector diagrams of gear pairs (Prof. S. Radzevich, circa 2008 [1]) (\#14). Vector diagrams of gear pairs with constant values of the center-distance, $C$, the crossed-axes angle, $\Sigma$, and the gear ratio, $u$, the so-called $C \Sigma u$-constant gear pairs, as well, as the socalled $C \Sigma u$-variable gear pairs, are covered by the classification. The classification of the gear pairs was further evolved to a scientific classification of gear pairs themselves. 


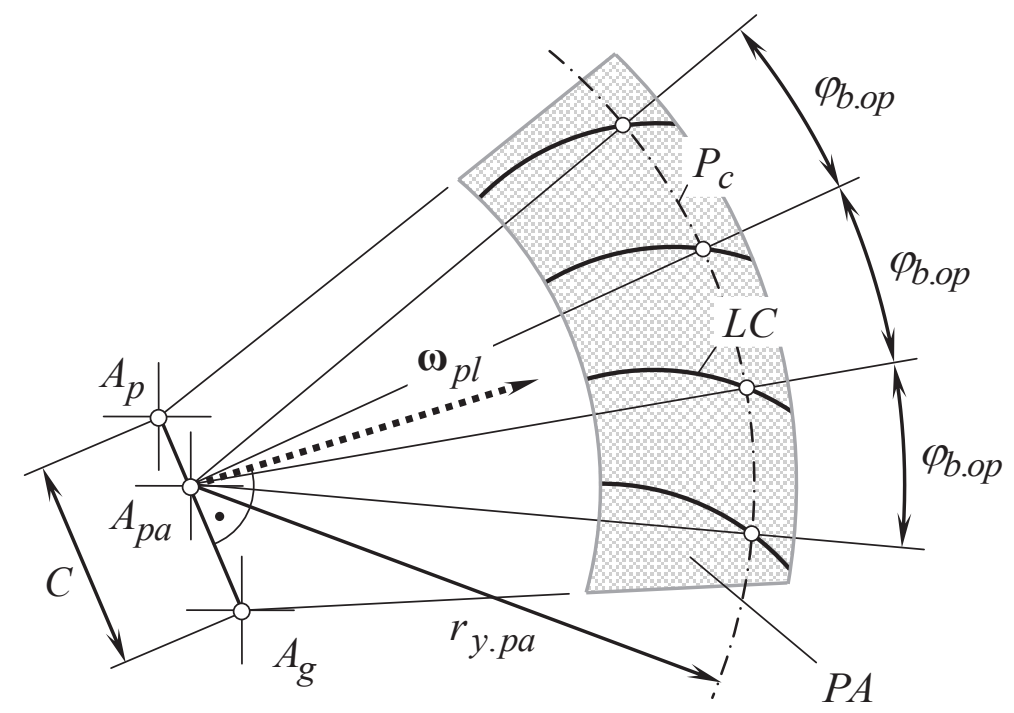

Fig. 9. On the concept of equal angular base pitches of a gear and a mating pinion to an operating angular base pitch of the gear pair. (Adapted from [1]).

\subsubsection{Perfect real gearing}

On the premise of the recent accomplishments in the scientific theory of gearing, a novel gear system is developed by S. Radzevich at around 2008 [1] (\#15). This gear system is commonly referred to as $S_{p r}$-gearing. If gears in a $S_{p r}$-gear pair are manufactured to the tolerances, then the gear pair is insensitive to the axes misalignment that do not exceed the tolerances for the axes misalignment. This means that the angular base pitch of the gear and that of the mating pinion are equal to the operating base pitch of the gear pair as long as the axes misalignment is within the tolerance band for the deviations.

\subsubsection{Equation of conjugacy of the interacting tooth flanks: for gearings of all kinds}

The considered in section 3.7 condition of conjugacy (see Fig. 8) of the interacting tooth flanks of a gear and a mating pinion, $\mathscr{O}$ and $\mathscr{P}$, provides a verbal description of the requirements to be meet by conjugate tooth flanks. Recently (2017), an equation of conjugacy of the tooth flanks, $\mathscr{O}$ and $\mathscr{P}$, was derived (Prof. S. Radzevich, circa 2008 [1]) (\#16):

$$
\mathbf{p}_{l n} \times \mathbf{V}_{m} \cdot \mathbf{n}_{g}=0
$$

Here is designated (Fig. 10): $\mathbf{p}_{l n}-$ is the unit vector along the axis of instant rotation, $P_{l n} ; \mathbf{V}_{m}-$ is the linear velocity vector of a point of a desirable line of contact, $L C_{\mathrm{des}}$, between the tooth flanks $\mathscr{O}$ and and $\mathbf{n}_{g}$ - is the unit vector of a common perpendicular at point of contact of the tooth flanks and

If the condition of conjugacy specified by Eq. (4) is fulfilled at every point of a desirable line of contact, $L C_{\text {des }}$, the gear pair designed this way is capable of transmitting smoothly an input steady rotation to the output shaft.

Actually, there is no need to check the condition of contact, $\mathbf{n} \cdot \mathbf{V}_{\Sigma}=0$, if the condition of conjugacy, $\mathbf{p}_{l n} \times \mathbf{V}_{m} \cdot \mathbf{n}_{g}=0$, is fulfilled.

\subsubsection{Accomplishments in the realm of non- circular gearings}

The most general case of non-circular gears with the crossing axes of rotation is analyzed. For the analysis, a reference system, associated with gear pair in a natural way is used [the axes of the reference system are along (a) the axis of instant rotation, $P_{l n}$, (b) the centerdistance, $\mathbb{\Phi}$, and (c) perpendicular to these two directions, $P_{l n}$ and $\Phi$ ]. In the analysis, the centerdistance $C$, the crossed-axes angle $\Sigma$, and the gear ratio $u$, are assumed variable. In particular cases, one or two variable parameters considered of a constant value. Under such the assumption, a classification of perfect $C \Sigma u$-gearing is developed (S. Radzevich, 2017) [1] (\#17).

\subsubsection{Favourable approximate gearings}

Easier manufacture is the principal advantage of approximate gearing over perfect gearing. Due to this advantage approximate gears will be used in the industry for a long while.

A theory of favorable approximate gearing can be (and will be) developed on the premises of the scientific theory of gearing [1]. Only in a such a scenario approximate gear pairs with favorable design parameters can be designed. 


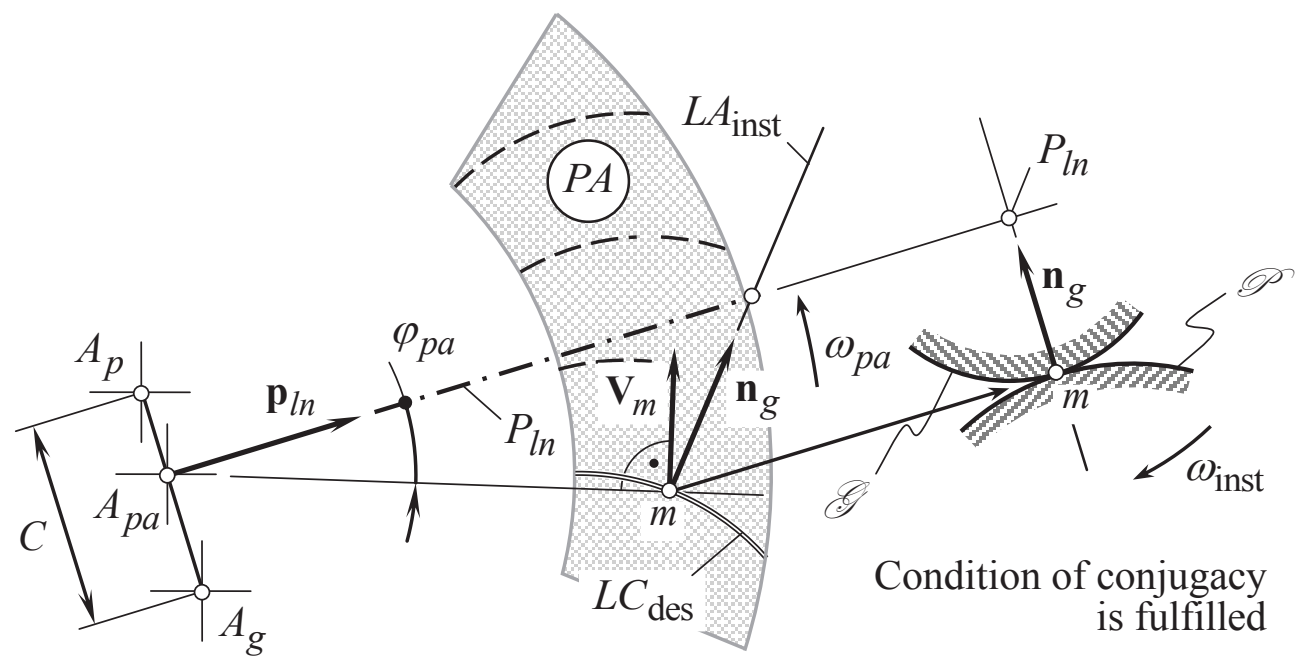

Fig. 10. On derivation of equation of conjugacy, $\mathbf{p}_{l n} \times \mathbf{V}_{m} \cdot \mathbf{n}_{g}=0$, of the tooth flanks, and $\mathscr{P}$. (After Prof. S.P. Radzevich, [1]).

\subsubsection{A tentative chronology of evolution of the scientific theory of gearing}

The discussion in section 3 of the paper allows to propose the following tentative chronology of evolution of the scientific theory of gearing (Fig. 11). The proposed chronology begins with an analysis of what was done in pre-Eulerian period of evolution of the gear art (the item \#0), and is followed by the fundamental contribution by L. Euler (the item \#1). The latter is considered as the origin of the scientific theory of gearing. The items \#2 through \#17 correspond to principal accomplishments in the theory that follow the item \#1. Where possible, corresponding names of the researchers and dates are associated with the corresponding accomplishments.

The listed accomplishments form the foundation of the self-consistent scientific theory of gearing (Radzevich, S.P., 2012, 2018).

A "parallel" line (the items \#3 through \#8) correspond to a wrong way of the evolution in gearing. Only approximate gears can be designed following this way. This is the dead end of evolution of the gear science.

The proposed chronology (Fig. 11) is open for further improvements. Constructive recommendations, comments, and concerns appreciated.

\subsubsection{On other efforts that pertain to the evolution of the scientific theory of gearing}

The author has turned his interest to the evolution of the gear science about a decade ago [12], [13].

In the recent years, numerous papers on the history of gearing (both, in English, and in Russian languages) have been authored/co-authored by Babichev, Barmina, Lagutin, Volkov, and others of Russia. All these publications are available in the public domain. A claim on the so-called "Russian school of theory of gearing" has been made by the Authors. It should be stressed here that all these publications are focused not on the principal accomplishments in the scientific theory of gearing.

The discussion in this paper along with the results of the earlier performed retrospective analysis on the history of evolution of the scientific theory of gearing [1], [2], reveal that this aggressive claim has been made with no sufficient validity. Are there significant accomplishments to the scientific theory of gearing (made by representatives of the so-called "Russian school of theory of gearing") that are not taken into account (and not indicated in the chart shown in Fig. 11)? Feel free to name them, if any! An appropriate comment will be helpful for the enhancement of our understanding of the evolution of the scientific theory of gearing.

In the published papers and monographs authored even by the leading Soviet/Russian gear researchers there is no evidence of understanding of the kinematics and geometry of (a) Novikov gearing; (b) spiroid gearing $^{\mathrm{e}}$ (and perfect worm gearing in a more general sense); (c) perfect intersected-axes, and (more generaly) crossed-axes gearing; (d) perfect gears with the axes misalignment, and so forth. They (e) still make no difference between enveloping surfaces and conjugate surfaces, (f) for decades, they carry out a meaningless research on gearing with a "closed line of contact that shrinks" when the gears rotate, a few more to mention. What can be expected from the less experienced gear researchers of Russia?

Prof. Ya.S. Davidov, one of the Soviet "coryphaeus" in the field of gearing, in his "Memories ..." correctly compared all the Russian gear theoreticians with the "swamp" (http://referat.znate.ru/text/index-8600.html). A following dialog took place between Prof. F.L. Litvin

e After about $40(!) \mathrm{PhD}$ thesis, and 5 (!) Dr. Sci thesis, are defended by these people, how is it permissible to ask a question: "What do we know about spiroid gearing"? What did you do all this time? 


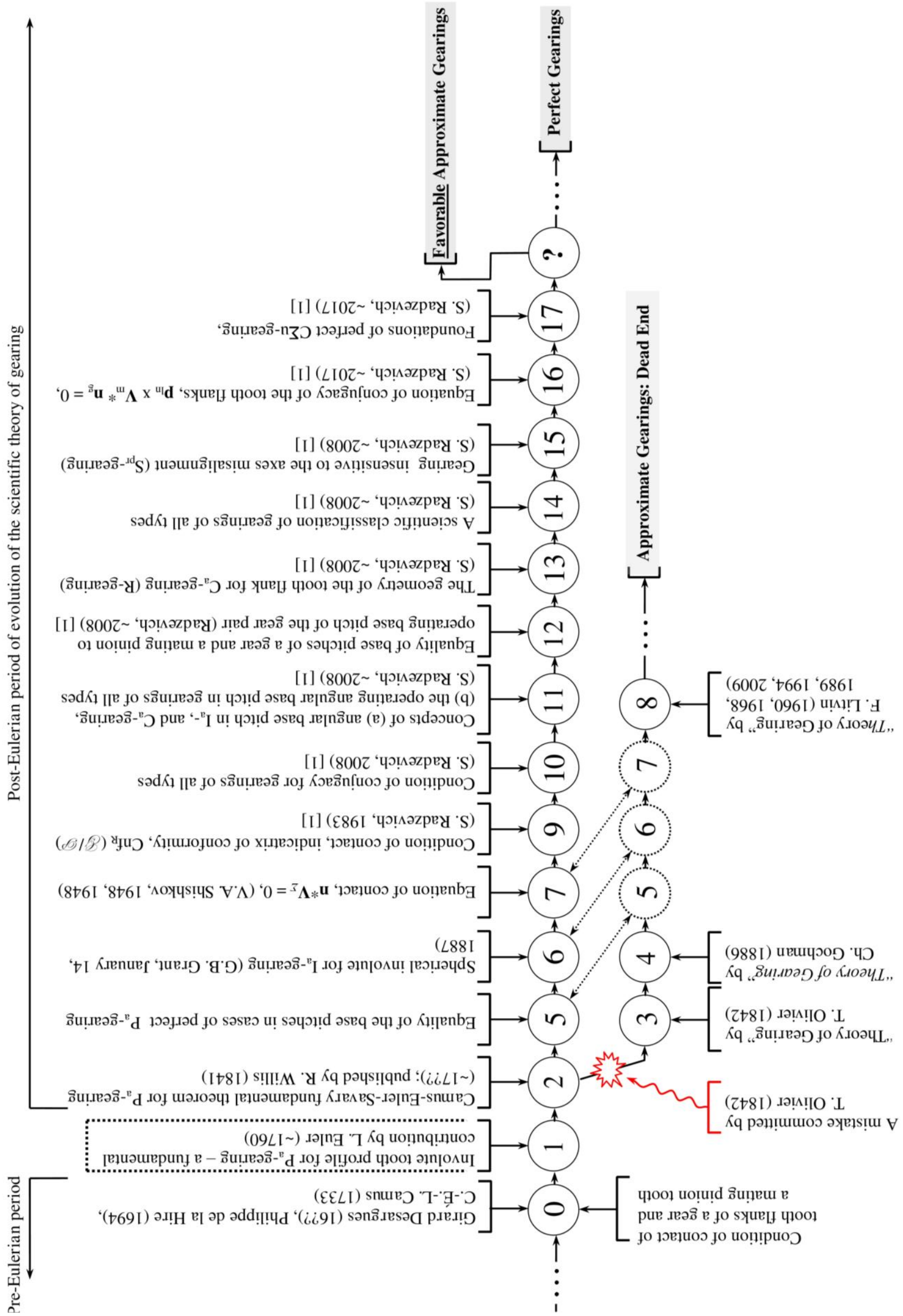

Fig. 11. Principal accomplishments in the scientific theory of gearing. (After Prof. S.P. Radzevich, [1]). and Prof. Ya.S. Davidov, when they were discussing 
the features of "Novikov gearing": "In one of the conversations with me F.L. Litvin very correctly compared the work of Novikov to the rock thrown into the swamp and caused a stirring of water" (It is likely the comparison of the gear community in the Soviet Union/Russia with a "swamp" makes sense). Can someone ignore this opinion of two well-known Soviet/Russian gear researchers (of Prof. F.L. Litvin, and Prof. Ya.S. Davidov), when they have compared all the Russian gear theoreticians with the "swamp"? This comparison is one more evidence of that the claim on the so-called special "Russian school of theory of gearing" is at least doubtful, if not to say more.

The just made conclusion has to be taken into account when the readers meet the meaningless term "Russian school of theory of gearing" (as well as similar terms introduced by Russians in the recent years: "classical school of theory of gearing" and "the gold age of theory of gearing"). In the meantime, experienced readers are skeptical with that and are commonly having a laugh when they read about the so-called "Russian school of theory of gearing" [14].

\section{Concluding remarks}

All (or at least, almost all) the principal accomplishments in the scientific theory of gearing are identified, and are briefly overviewed in the paper. To the best of the author's knowledge, all the principal accomplishments are covered in the paper. Where possible, the accomplishments are attributed with corresponding names of the gear researchers, and dates when the contribution has been done ${ }^{\mathrm{f}}$. These accomplishments form the foundation of the selfconsistent scientific theory of gearing (proposed by Radzevich, S.P. circa 2008 [1]). The scientific theory of gearing is not threatened with destruction, but only superstructure and development are extected (every scientific theory features this property).

A tentative chronology of the evolution of the scientific theory of gearing is proposed.

The paper is helpful for better understanding the fundamental principles of gearing.

\section{References:}

1. Radzevich, S.P., Theory of Gearing: Kinematics, Geometry, and Synthesis, $2^{\text {nd }}$ Edition, revised and expanded, CRC Press, Boca Raton, FL, 2018, 934 pages. [First Edition: Radzevich, S.P., Theory of Gearing: Kinematics, Geometry, and Synthesis, CRC Press, Boca Raton, Florida, 2012, 743 pages].

2. Radzevich, S.P., "A Brief Overview on the Evolution of the Scientific Theory of Gearing: A Preliminary Discussion". In: Proceedings of International Conference on Gears 2015, October 5-7, 2015, Technische Universität München (TUM),

\footnotetext{
${ }^{\mathrm{f}}$ Except of the contributions by L. Euler, the contributions by other members of the Hall of Fame at the Gear Research center (The University of Illinois at Chicago) are out of the scope of the scientific theory of gearing, and, thus, are not discussed here.
}

Garching (near Munich), Germany, 2015, pp.10351046.

3. Camus, C.-É.-L., "Sur la figure des dents des rouës, et des ai les des pignons, pour rendre les horloges plus parfaites", 1733.

4. Euler, L., De Optissima Figura Rotarum Dentibus Tribuenda. In: Novi Commentarii academiae scientiarum Petropolitanae, 1750, pp. 119-135.

5. Euler, L., Supplementum. De figura dentium rotarum. In: Novi Commentarii academiae scientiarum Petropolitanae 11, 1767, pp. 207-231.

6. Willis, R., Principles of Mechanisms, Designed for the Use of Students in the Universities and for Engineering Students Generally, London, John W. Parker, West Stand, Cambridge: J. \& J.J. Deighton, 1841, 446p.

7. Olivier, T., Théorie Géométrique des Engrenages destinés, Bachelier, Paris 1842, 132 pages.

8. Gochman, H.I., Theory of Gearing Generalized and Developed Analytically, Odessa, 1886, 229 pages.

9. U.S. Pat. No. 407.437. Machine for Planing Gear Teeth./G.B. Grant, Filed: January 14, 1887 (serial No. 224,382), Patented: July 23, 1889.

10. Shishkov, V.A., "Elements of the Kinematics of Generating, and the Conjugation in Gearing", in: Theory and Computation of Gears, Vol. 6, Leningrad, LONITOMASH, 1948, p. 123.

11. Shishkov, V.A., Generation of Surfaces in Continuous-Indexing Methods of Surface Machining, Moscow, Mashgiz, 1951, 152 pages.

12. Radzevich, S.P., "Concisely on Kinematical Method and on History of the Equation of Contact $\mathbf{n} * \mathbf{V}=0$ ", Theory of Machines and Mechanisms, 2010, No. 1, Vol. 8, pp. 42-51.

http://tmm.spbstu.ru/15/radzevich_15.pdf

13. S.P. Radzevich, S.P., "Experience gained from reading master's thesis by Ch.I. Gochman "Theory of gearing, generalized and evolved by analysis"", in: Theory of Machines and Mechanisms, 2011, Vol. 9, Issue 1, pp. 33-43.

http://tmm.spbstu.ru/17/radzevich_17.pdf

14. Radzevich, S.P., "A Brief Overview on the Evolution of Gear Art: Design and Production of Gears, Gear Science", Chapter 11, pp. 418-485 in: Radzevich, S.P., Editor, Advances in Gear Science and Manufacture, CRC Press, Boca Raton, FL, 2019, 570 pages.

\section{Bibliography:}

Babichev, D. T., Lagutin, S. A., Barmina, N. A., "Overview of the Works of the Russian School of Theory of and the Geometry of Gearing. Part 1. Origins of the Theory of Gearing, and its Heyday Time in 19351975", Theory of Mechanisms and Machines, Vol. 14, 2016 №3(31), pp. 101-134.

Babichev, D. T., Lagutin, S. A., Barmina, N. A., "Overview of the Works of the Russian School of Theory of and the Geometry of Gearing. Part 2. 
Development of the Classical Theory of Gearing and Establishment of the Theory of Real Gearing in 19762000", Theory of Mechanisms and Machines, Vol. 15, 2017 №3(35), pp. 86-119.

Babichev, D. T., Volkov, A. E., "History of Evolution of the Theory of Gearing", Journal of Scientific and Technological Development, № 5 (93), 2015, c. 25-42.

Crosher, W.P., A Gear Chronology: Significant Events and Dates Affecting Gear Development, Xlibris Corporation, 2014, 260 pages.

da Vinci, L., The Madrid Codices, Volume 1, 1493, Facsimile Edition of "Codex Madrid 1", original Spanish title: Tratado de Estatica y Mechanica en Italiano, McGraw Hill Book Company, 1974.

de la Hire, P., Mémoires de Mathématique et de Physique, Impr. Royale, Paris, 1694.

Derek de Solla Price, "Gears from the Greeks. The Antikythera Mechanism: A Calendar Computer from ca. 80 B. C.", Transactions of the American Philosophical Society, Vol. 64, No. 7 (1974), pp. 1-70.

Dürer, A., Underweysung der Messung mit dem Zirckel und Richtscheyt, 1525, pp. 6-17.

Field, J.V., Wright M.T., "The early history of mathematical gearing", Endeavour, Volume 9, Issue 4, 1985, Pages 198-203.

Gear History - where do gearboxes originate? APEX DYNAMICS, https://www.apexdyna.nl/en/news/gear-history/

Goldfarb, V.I., "What we know about spiroid gearing", in: Proceedings of the International Conference on Mechanical Transmissions, China, Vol. 1, Science Press, 2006, pp.19-26.

History of Gears, Nordex, Inc., https://nordex.com/about/history/.

History of Gears, UGEARS mechanical models, Aug. 04, 2017, https://ugears.online/blogs/news/historyof-gears.

Lagutin, S.A., N. Barmina, N.A., "Prof. F.L. Litvin: Contribution to the Formation of the Russian School of the Theory of Gearing", in: Goldfarb, V., and Barmina, Editors: Theory and Practice of Gearing and Transmissions, Mechanisms and Machine Science 34, Springer International Publishing Switzerland 2016, pages 19-36.

Lewis, M.J.T., "Gearing in the ancient world", Endeavour, Volume 17, Issue 3, 1993, pages 110-115.

Maddison, F., "Early mathematical wheelwork: Byzantine calendrical gearing", Nature, volume 314, pages316-317 (1985).

Silich, A.A., Cylindrical Novikov Gearing, LAP Lambert Academic Publishing, 2013, 100 pages.

Silich, A.A., Novikov Gearing: Geometrical Calculation of Cylindrical Gearings, Monograph, Tiumen', Publisher of the Tiumen' Institute of Industry, 2016, 79 pages.

Silich, A.A., The Development of a Geometrical Theory of Design of Novikov Gearing, and of the Tooth Flanks Generation Process, Doctoral Thesis, Kurgan State University, Kurgan, 1999, 534 pages.
Volkov, A.E., Babichev D.T., "History of Gearing Theory Development", 25th Working Meeting of IFToMM Permanent Commission for Standardization of Terminology on MMS, Saint-Petersburg, Russia, June 23 - 29, 2014, pp. 71-102.

Willis, R., Principles of Mechanisms, Designed for the Use of Students in the Universities and for Engineering Students Generally, London, John W. Parker, West Stand, Cambridge: J. \& J.J. Deighton, 1841, 446 pages.

Woodbury, R.S., History of the Gear-Cutting. A Historical Study in Geometry and Machine, The M.I.T. Press, 1958, $135 \mathrm{p}$. 